\title{
Influence of Severe Drought on Leaf Response in ABA Contrasting Tomato Genotypes (Wild Type and flacca Mutant) ${ }^{\dagger}$
}

\author{
Ivana Petrović ${ }^{1, *}$, Zorica Jovanović ${ }^{1}$, Radmila Stikić ${ }^{1}$, Milena Marjanović ${ }^{1}$ and Slađana Savić ${ }^{2}$ \\ 1 Faculty of Agriculture, University of Belgrade, 11080 Belgrade, Serbia; zocaj@agrif.bg.ac.rs (Z.J.); \\ rstikic@gmail.com (R.S.); milena.pauk@gmail.com (M.M.) \\ 2 Faculty of Biofarming, The John Naisbitt University, 11070 Belgrade, Serbia; bonita.sladja@gmail.com \\ * Correspondence: ivanappetrovic@gmail.com; Tel.: +381-64-951-8147 \\ + Presented at the 1st International Electronic Conference on Plant Science, 1-15 December 2020; Available \\ online: https://iecps2020.sciforum.net/.
}

check for updates

Citation: Petrović, I.; Jovanović, Z.; Stikić, R.; Marjanović, M.; Savić, S. Influence of Severe Drought on Leaf Response in ABA Contrasting Tomato Genotypes (Wild Type and flacca Mutant). Biol. Life Sci. Forum 2021, 4, 96. https://doi.org/10.3390/ IECPS2020-08867

Academic Editor: Yoselin Benitez-Alfonso

Published: 3 December 2020

Publisher's Note: MDPI stays neutral with regard to jurisdictional claims in published maps and institutional affiliations.

Copyright: (C) 2020 by the authors. Licensee MDPI, Basel, Switzerland. This article is an open access article distributed under the terms and conditions of the Creative Commons Attribution (CC BY) license (https:/ / creativecommons.org/licenses/by/ $4.0 /)$.

\begin{abstract}
The reaction of leaf growth to drought stress is controlled by various hormones, among which ABA is one of the most important. The aim of this study was to examine the effects of ABA deficiency on tomato leaf response under severe drought stress. Therefore, ABA-mutant (flacca) and wild type (Ailsa Craig) were selected for research and in the stage of second flower truss anthesis plants were exposed to severe water deficit. The effects of severe drought on wild-type leaves and flacca mutant showed that, as a result of reduced ABA concentrations, flacca plants were exposed to a higher degree of stress than wild-type leaves, which had a negative impact on the examined physiological and biochemical parameters. Severe drought caused stomatal closure, decreased water potential, specific leaf area, and chlorophyll concentrations in the leaves in both genotypes, but this was more pronounced in the mutant. Wild-type plants have accumulated more vitamin $\mathrm{C}$ and $\mathrm{ABA}$ and have a higher total antioxidant capacity in the leaves in dry conditions than flacca mutants, which contribute to their better adaptive response to stress. Based on this, it can be assumed that the ABA mutation has led to a decrease in the capacity for oxidative stress products caused by severe drought stress.
\end{abstract}

Keywords: tomato; flacca; Ailsa Craig; severe drought; leaf

\section{Introduction}

Drought is one of the most abiotic stress factors which affects plants on a physiological, biochemical, and molecular level, and triggers different plant defense mechanisms such as reduction of transpiration, increase of water absorption, osmotic adjustment, increased antioxidant system, and drought tolerance [1]. The impact of drought on tomato growth and development largely depends on the stage of ontogenesis when exposed to water deficit [2]. Leaf growth is one of the most drought-sensitive processes in plants, leading to a reduced leaf area, but it also induces changes in parameters related to the leaf area-leaf dry mass ratio [3]. Drought-induced stomatal closure has an impact on net photosynthesis, but it also adversely affects the pigment system and photosynthetic electron transport and increases the risk of photooxidative stress [4].

Abscisic acid (ABA), as a "stress" hormone whose concentration increases under abiotic stresses, especially drought, plays an important role in regulating growth and development of plants; it affects water regime, stoma reactions and photosynthesis, leaf and root growth, and changes in gene expression that control plant adaptive response [5]. In the study of the role and mechanisms of plant hormones in plants, mutants with reduced hormone biosynthesis are usually used. The aim of the presented study is to analyze the leaf response in $\mathrm{ABA}$ contrasting tomato genotypes by following physiological and biochemical changes under severe drought conditions. In order to reveal the role of hormone ABA in plant reactions to drought, two tomato genotypes were used: wild-type Ailsa Craig and 
ABA-deficient mutant flacca with reduced amount of ABA due to the changes in the activity of ABA-aldehyde oxidase [6].

\section{Experiments}

\subsection{Experiment}

The seeds of tomato wild-type Ailsa Craig and ABA-deficient mutant flacca were obtained from IPK Gatersleben Genebank and germinated in substrate Potgrond H-Klasmann (Germany). In the phase of the 5th leaf, plants were planted in pots filled with the mixture of substrate (Terracult "Blue line", Terracult International GmbH, Hennef, Germany) and perlite. The plants were grown in controlled conditions in plant growth chamber at the Faculty of Agriculture, University of Belgrade, Serbia, at the following conditions: daily temperature between 25 and $28{ }^{\circ} \mathrm{C}$, in $16 / 8$ light regimens, at $250 \mu \mathrm{mol} \mathrm{m}{ }^{-2} \mathrm{~s}^{-1}$ PAR. Plants were fertilized every 14 days with liquid fertilizers.

In the phase of anthesis of the 2nd flower truss, plants were divided into two treatments ( 9 plants per treatment and genotype):

1. Control group - plants were fully irrigated from the beginning to the end of the experiment (36\% of volumetric water content);

2. Severe drought — plants were fully irrigated to the phase of the 2nd flower truss, when severe drought treatment started (10-11\% of volumetric water content) until the end of the experiment.

Water content of the substrate was measured daily by ML3 ThetaProbe Soil Moisture sensor (Delta-T Device, Ltd., Cambridge, UK), in order to obtain the amount of water for irrigation.

\subsection{Physiological Parameters}

Stomatal conductance was measured by AP4 Leaf Porometer (Delta-T Device, Ltd., Cambridge, UK), while the leaf water potential was measured by using a pressure chamber [7]. At the end of the experiment, leaves were dried and dry matter content was determined. Leaf area was measured by LI-3100 area meter (LI-COR, Lincoln, NE, USA) and specific leaf area (SLA) was calculated according to Hunt [8]. Leaf chlorophyll content was measured in the phases of anthesis, mature green, and turning phase of fruit development by Dualex Force-A device.

\subsection{Biochemical Analysis}

For biochemical analysis, leaves were ground to powder in liquid nitrogen. Analysis of ascorbic acid was performed following the protocol of Stevens et al. [9]. Antioxidant capacity was measured by modified protocol [10]. Abscisic acid (ABA) concentration was measured by ELISA test following the protocol of Asch [11].

\section{Results}

\subsection{Physiological Parameters}

\subsubsection{Stomatal Conductance and Leaf Water Potential}

Obtained results showed that stomatal conductance and leaf water potential were not statistically different among investigated tomato genotypes under control conditions, while under drought stress, genotype-related differences were expressed (Table 1). Severe drought caused the decrease of stomatal conductance in both genotypes, but the effect was more expressed in wild-type Ailsa Craig compared to mutant flacca $(83 \%$ and $62 \%$, respectively). On the contrary, the decrease of water potential values under drought was more expressed in mutant flacca (from -0.33 to $-1.55 \mathrm{MPa}$ ) compared to wild type (from -0.31 to $-1.22 \mathrm{MPa})$. 
Table 1. Stomatal conductance and leaf water potential under optimal and drought conditions (mean $\pm \mathrm{SE}$; level of significance $\left.{ }^{* * *} p \leq 0.001\right)$.

\begin{tabular}{ccccc}
\hline & \multicolumn{2}{c}{ Stomatal Conductance $\left.\mathbf{( m m o l ~ m}^{-\mathbf{2}} \mathbf{~ s}^{-\mathbf{1}}\right)$} & \multicolumn{2}{c}{ Leaf Water Potential (-MPa) } \\
\hline Genotype & Control & Drought & Control & Drought \\
\hline Ailsa Craig & $961.25 \pm 7.66$ & $160.37 \pm 2.05^{* * *}$ & $-0.31 \pm 0.01$ & $-1.22 \pm 0.04^{* * *}$ \\
flacca & $1038.75 \pm 7.66$ & $396.87 \pm 7.84^{* * *}$ & $-0.33 \pm 0.01$ & $-1.55 \pm 0.06^{* * *}$ \\
\hline
\end{tabular}

\subsubsection{Specific Leaf Area and Dry Matter Content}

Genotype-specific differences among specific leaf area (SLA) values were expressed in both control and drought conditions (Table 2). Under control conditions, mutant flacca had $32 \%$ lower SLA in comparison to wild type. Severe drought caused higher reduction of SLA in mutant flacca $(27 \%)$ than in wild type (15\%). Leaf dry matter content was not statistically different among genotypes in control conditions (Table 2), but under drought stress, reducing effect was more expressed in mutant flacca (49\%) compared to Ailsa Craig (36\%).

Table 2. Specific leaf area and leaf dry matter content under optimal and drought conditions (mean $\pm \mathrm{SE}$; level of significance ${ }^{* * *} p \leq 0.001$ ).

\begin{tabular}{ccccc}
\hline & \multicolumn{2}{c}{ Specific Leaf Area-SLA $\left(\mathbf{c m}^{2} / \mathbf{g}\right)$} & \multicolumn{2}{c}{ Dry Matter Content (\%) } \\
\hline Genotype & Control & Drought & Control & Drought \\
\hline Ailsa Craig & $158.83 \pm 9.66$ & $135.58 \pm 10.12^{* * *}$ & $9.93 \pm 0.17$ & $13.51 \pm 0.33^{* * *}$ \\
flacca & $108.54 \pm 3.71$ & $78.84 \pm 2.76^{* * *}$ & $10.39 \pm 0.19$ & $15.53 \pm 0.30^{* * *}$ \\
\hline
\end{tabular}

\subsubsection{Chlorophyll Content}

Analysis of chlorophyll content in the leaves at different stages of fruit development in optimal conditions showed that both genotypes in anthesis stage had similar amounts of chlorophyll, while in later stages, chlorophyll accumulated more in flacca leaves (Table 3). Severe drought stress induced the decrease of leaf chlorophyll content in mature green phase (15\% for flacca, $6 \%$ for Ailsa Craig), while a pronounced effect was observed in the turning phase of fruit development (12\% for wild type and 19\% for flacca mutant).

Table 3. Chlorophyll content in the leaves at different stages of tomato fruit development under optimal and drought conditions (mean $\pm \mathrm{SE}$; levels of significance ${ }^{*} p<0.05,{ }^{* *} p<0.01,{ }^{* * *} p \leq 0.001$ ).

\begin{tabular}{cccc}
\hline & & \multicolumn{2}{c}{ Chlorophyll Content $\left(\boldsymbol{\mu g} / \mathbf{c m}^{\mathbf{2}}\right)$} \\
\hline Genotype & Phase of Fruit Development & Control & Drought \\
\hline Ailsa Craig & Anthesis & $32.58 \pm 0.87$ & \\
& Mature green & $36.15 \pm 0.92$ & $33.90 \pm 0.81^{*}$ \\
\multirow{2}{*}{ flacca } & Turning phase & $39.70 \pm 0.84$ & $34.88 \pm 0.71^{*}$ \\
& Anthesis & $33.18 \pm 0.70$ & \\
& Mature green & $41.23 \pm 0.93$ & $35.14 \pm 0.87^{* *}$ \\
& Turning phase & $48.88 \pm 0.63$ & $39.49 \pm 0.95^{* * *}$ \\
\hline
\end{tabular}

\subsection{Biochemical Parameters}

Vitamin C, Antioxidant Capacity, and ABA Content

Analysis of vitamin $C$ content showed significant differences among genotypes under control and stress conditions (Table 4). Severe drought induced accumulation of vitamin C in both genotypes ( $21 \%$ for Ailsa Craig and $9 \%$ for flacca) in comparison to the control. Under stress conditions, the increase of antioxidant capacity was more pronounced in the leaves of wild type (51\%) than in flacca mutant (30\%). Specific genotypic differences were observed in leaf ABA content under control conditions, since ABA-deficient mutant flacca had 37\% less ABA than wild type (Table 4). Severe drought induced accumulation 
of $\mathrm{ABA}$ that was more expressed in wild type (increase of $242 \%$ ) compared to the mutant flacca $(123 \%)$.

Table 4. Vitamin C content, antioxidant capacity, and ABA content under optimal and drought conditions (Mean \pm SE; levels of significance $\left.{ }^{* * *} p \leq 0.001\right)$.

\begin{tabular}{ccccccc}
\hline & \multicolumn{2}{c}{ Vitamin C (mg/100 g FW) } & \multicolumn{2}{c}{$\begin{array}{c}\text { Antioxidant Capacity } \\
(\mu \text { mol TEAC/100 g FW) }\end{array}$} & \multicolumn{2}{c}{ ABA (ng/g FW) } \\
\hline Genotype & Control & Drought & Control & Drought & Control & Drought \\
\hline Ailsa Craig & $70.53 \pm 2.35$ & $85.47 \pm 2.30^{* * *}$ & $79.66 \pm 1.93$ & $120.45 \pm 1.60^{* * *}$ & $387.93 \pm 8.26$ & $1326.99 \pm 42.6^{* * *}$ \\
flacca & $55.39 \pm 1.35$ & $60.61 \pm 1.57$ & $81.96 \pm 1.56$ & $106.70 \pm 2.11^{* * *}$ & $243.36 \pm 8.57$ & $541.70 \pm 17.87^{* * *}$ \\
\hline
\end{tabular}

\section{Discussion}

\subsection{Physiological Processes}

Stomatal conductance and leaf water potential are the indicators of plant water regime, but also can be used for selection of tomato-resistant genotypes for drought conditions [12]. Literature data confirm that drought stress induces stomatal closure and causes decrease of turgor and water potential in tomato plants $[13,14]$. Our results for stomatal conductance are in correspondence with data reported by Nankishore and Farrell [15] in different tomato genotypes under severe drought stress. Previous studies have confirmed that genotype flacca was more affected by dehydration compared to Ailsa Craig [16] and our results are in agreement with this, since the mutant has lower water potential than wild type under drought (Table 1). Investigation of leaf tomato response under severe drought showed that the decrease of stomatal conductance was followed by increased accumulation of ABA in the leaves [17]. Differences in stomatal conductance between the investigated genotypes under stress conditions in our experiment could be related to different accumulation of $\mathrm{ABA}$ in the leaves (Table 4), where the reactions of the mutant are related to lower ABA concentration compared to wild type.

Our results also showed that severe drought induces decrease of specific leaf area, which is in correspondence with literature data [18]. The effect was more pronounced in flacca mutants (Table 2); this could be related to smaller leaf area due to less growth and curling of leaves $[19,20]$. The increase of the dry matter content in the leaves under severe drought was significantly higher in the flacca genotype than in wild type (Table 2). The application of different degrees of drought stress in tomatoes showed that the leaves have higher dry matter content under severe stress [21], which is in line with the data obtained in our experiment. An increase in the dry matter content in the leaves indicates changes in hydration in the leaf tissues that could be a consequence of the concentration effect, but also the effect of osmotic adjustment [22].

Chlorophyll content is a parameter which indicates the efficiency of the photosynthesis process. Severe drought stress had a negative effect on the accumulation of chlorophyll in the leaves in both genotypes at different stages of fruit development (Table 3) which is in agreement with literature data [23]. The greatest effect in both genotypes was observed in the earlier phase of fruit ripening (the turning phase) which indicates the relationship between chlorophyll biosynthesis and the fruit-ripening process [24]. A greater decrease in the chlorophyll content in mutant flacca indicates a greater sensitivity of this genotype to drought stress. These data are consistent with data of Sivakumar et al. [25], who showed that drought stress induced a greater decrease in chlorophyll content in sensitive genotypes than in tolerant genotypes. Exogenous application of low concentrations of ABA in different tomato genotypes led to an increase in the content of chlorophylls in the leaves [26]. Therefore, it can be assumed that the increase in ABA content in the leaves of both genotypes resulted in a small increase in chlorophyll content under severe drought in the turning phase (Table 3), compared to the green fruit phase. 


\title{
4.2. Biochemical and Metabolic Processes
}

Severe drought stress is often accompanied by oxidative stress, the production of reactive oxygen species (ROS), and activation of antioxidant defense systems. Our results showed that an increase of vitamin C, as well as antioxidant activity in the leaves, was more pronounced in the wild type than in the flacca mutant. Severe drought stress often increases the activity of the enzymes superoxide dismutase, peroxidase, and catalase, as well as the antioxidative activity in tomato plants $[23,27]$.

The capacity for antioxidant defense is closely related to ABA accumulation. ABAdeficient tomato mutants (notabilis and sitiens) are characterized by increased peroxidase activity, which indicates the association between this enzyme and ABA concentration [28]. Ünyayar and Çekıç [29] also showed that in the leaves of the notabilis, antioxidant activity can be increased by applying drought stress or by exogenous ABA. The relationship between antioxidative activity and ABA may explain genotypic response in our experiments, since ABA mutation in flacca could be responsible for reduced antioxidant activity and limited capacity for ROS removal under severe stress (Table 4).

One of the first biochemical changes in plants under drought stress is accumulation of $\mathrm{ABA}$ as a chemical signal of drought that affects plant response. Moles et al. [14] found an increase in ABA concentration in leaves and roots in different tomato genotypes under drought stress conditions. Our results showed that drought-induced accumulation of ABA in the leaves was more pronounced in wild type compared to flacca mutant (Table 4); this could be explained as a specific stomata and leaf response. Investigation of gene expression in Ailsa Craig leaves indicate a synergistic effect of signaling pathways for ABA and ethylene, while in flacca the expression of the NCED gene was reduced and EIL1 was increased, which indirectly implies an increase in the concentration of ethylene [30]. Therefore, the explanation for the smaller leaf area and mass of flacca mutant or specific leaf response compared to the wild type may be due to decreased ABA production or increased ethylene concentration.

\section{Conclusions}

Investigations into the effect of severe drought on tomato leaf indicated a specific genotypic response. Leaves of flacca mutant had lower water potential and higher stomatal conductance in drought conditions and were therefore exposed to a higher degree of water stress compared to the wild type. Under severe drought, a decrease in specific leaf area as an indicator of leaf growth and chlorophyll concentration was found in the leaves in both genotypes, but the effect was more pronounced in the mutant than in wild type. Water deficit induced an increase in total antioxidant capacity, vitamin C, and ABA content, which was more pronounced in the leaves of wild type. These results indicated that the ABA mutation led to a reduced capacity for defense against oxidative stress that could occur during severe drought.

Author Contributions: Z.J. and R.S. conceived and designed the experiments; I.P. and S.S. performed the experiments; Z.J., I.P. and M.M. analyzed the data; M.M. contributed analysis tools; Z.J. and I.P. wrote the paper. All authors have read and agreed to the published version of the manuscript.

Acknowledgments: This study was supported by the Ministry of Education, Science and Technological Development of the Republic of Serbia (Grant No. 451-03-68/2020-14/200116).

Conflicts of Interest: The authors declare no conflict of interest. The founding sponsors had no role in the design of the study; in the collection, analyses, or interpretation of data; in the writing of the manuscript, and in the decision to publish the results.

\author{
Abbreviations \\ The following abbreviations are used in this manuscript: \\ ABA Abscisic acid \\ FW Fresh weight
}


SLA Specific leaf area

ROS Reactive oxygen species

TEAC Trolox equivalent antioxidant capacity

\section{References}

1. Kamanga, R.M.; Mbega, E.; Ndakidemi, P. Drought Tolerance Mechanisms in Plants: Physiological Responses Associated with Water Deficit Stress in Solanum lycopersicum. ACST 2018, 6, 362. [CrossRef]

2. Chen, S.; Zhou, Z.J.; Andersen, M.N.; Hua, T. Tomato yield and water use efficiency-Coupling effects between growth stage specific soil water deficit. Acta Agric. Scand. 2015, 65, 460-469. [CrossRef]

3. Patanè, C.; Saita, A. Biomass, fruit yield, water productivity and quality response of processing tomato to plant density and deficit irrigation under a semiarid Mediterranean climate. Crop Pasture Sci. 2015, 66, 224-234. [CrossRef]

4. Muñoz, P.; Munné-Bosch, S. Photo-Oxidative Stress during Leaf, Flower and Fruit Development. Plant Physiol. 2018, 176, 1004-1014. [CrossRef] [PubMed]

5. Sah, S.K.; Reddy, K.R.; Li, J. Abscisic Acid and Abiotic Stress Tolerance in Crop Plants. Front. Plant Sci. 2016, 7, 571. [CrossRef]

6. Sagi, M.; Fluhr, R.; Lips, S. Aldehyde oxidase and xanthine dehydrogenase in a flacca tomato mutant with deficient abscisic acid and wilty phenotype. Plant Physiol. 1999, 120, 571-577. [CrossRef]

7. Scholander, P.F.; Bradstreet, E.D.; Hemmingsen, E.A.; Hammel, H.T. Sap pressure in vascular plants: Negative hydrostatic pressure can be measured in plants. Science 1965, 148, 339-346. [CrossRef] [PubMed]

8. Hunt, R. Plant Growth Curves: The Functional Approach to Plant Growth Analysis; Cambridge University Press: London, UK, 1982.

9. Stevens, R.; Buret, M.; Garchery, C.; Carretero, Y.; Causse, M. Technique for Rapid, Small-Scale Analysis of Vitamin C Levels in Fruit and Application to a Tomato Mutant Collection. J. Agric. Food Chem. 2006, 54, 6159-6165. [CrossRef]

10. Re, R.; Pellegrini, N.; Proteggente, A.; Pannala, A.; Yang, M.; Rice-Evans, C. Antioxidant activity applying an improved ABTS radical cation decolorization assay. Free Radic. Biol. Med. 1999, 26, 1231-1237. [CrossRef]

11. Asch, F. Laboratory Manual on Determination of Abscisic Acid by Indirect Enzyme Linked Immuno Sorbent Assay (ELISA); Technical Series 1-2000; The Royal Veterinary and Agricultural University: Copenhagen, Denmark, 2000; pp. 1-21.

12. Borba, M.E.A.; Maciel, G.M.; Fraga Júnior, E.F.; Machado Júnior, C.S.; Marquez, G.R.; Silva, I.G.; Almeida, R.S. Gas exchanges and water use efficiency in the selection of tomato genotypes tolerant to water stress. Genet. Mol. Res. 2017, 16, 1-9. [CrossRef] [PubMed]

13. Calcagno, A.M.; Rivas, M.; Castrillo, M. Structural, physiological and metabolic integrated responses of two tomato (Solanum lycopersicum L.) cultivars during leaf rehydration. Aust. J. Crop Sci. 2011, 5, 695-701.

14. Moles, T.M.; Mariotti, L.; De Pedro, L.F.; Guglielminetti, L.; Picciarelli, P.; Scartazza, A. Drought induced changes of leaf-to-root relationships in two tomato genotypes. Plant Physiol. Biochem. 2018, 128, 24-31. [CrossRef] [PubMed]

15. Nankishore, A.; Farrell, A.D. The response of contrasting tomato genotypes to combined heat and drought stress. J. Plant Physiol. 2016, 202, 75-82. [CrossRef] [PubMed]

16. Muñoz-Espinoza, V.A.; López-Climent, M.F.; Casaretto, J.A.; Gómez-Cadenas, A. Water Stress Responses of Tomato Mutants Impaired in Hormone Biosynthesis Reveal Abscisic Acid, Jasmonic Acid and Salicylic Acid Interactions. Front. Plant Sci. 2015, 6, 997. [CrossRef]

17. Tamburino, R.; Vitale, M.; Ruggiero, A.; Sassi, M.; Sannino, L.; Arena, S.; Costa, A.; Batelli, G.; Zambrano, N.; Scaloni, A.; et al. Chloroplast proteome response to drought stress and recovery in tomato (Solanum lycopersicum L.). BMC Plant Biol. 2017, 7, 3-14. [CrossRef] [PubMed]

18. Rigano, M.M.; Arena, C.; Di Matteo, A.; Sellitto, S.; Frusciante, L.; Barone, A. Eco-physiological response to water stress of drought-tolerant and drought sensitive tomato genotypes. Plant Biosyst. 2016, 150, 682-691. [CrossRef]

19. Dodd, I.C.; Theobald, J.C.; Richer, S.K.; Davies, W.J. Partial phenotypic reversion of ABA-deficient flacca tomato (Solanum lycopersicum) scions by a wild-type rootstock: Normalizing shoot ethylene relations promotes leaf area but does not diminish whole plant transpiration rate. J. Exp. Bot. 2009, 60, 4029-4039. [CrossRef]

20. Nitsch, L.; Kohlen, W.; Oplaat, C.; Charnikhova, T.; Cristescu, S.; Michieli, P.; Wolters-Arts, M.; Bouwmeester, H.; Mariani, C.; Vriezen, W.H.; et al. ABA-deficiency results in reduced plant and fruit size in tomato. J. Plant Physiol. 2012, 169, 878-883. [CrossRef]

21. Wahb-Allah, M.A.; Alsadon, A.A.; Ibrahim, A.A. Drought Tolerance of Several Tomato Genotypes under Greenhouse Conditions. World Appl. Sci. J. 2011, 15, 933-940.

22. Al Hassan, M.; Martinez Fuertes, M.; Ramos Sanchez, F.J.; Vicente, O.; Boscaiu, M. Effects of Salt and Water Stress on Plant Growth and on Accumulation of Osmolytes and Antioxidant Compounds in Cherry Tomato. Not. Bot. Horti Agrobot. 2015, 43, 1-11. [CrossRef]

23. Yuan, X.K.; Yang, Z.Q.; Li, Y.X.; Liu, Q.; Han, W. Effects of different levels of water stress on leaf photosynthetic characteristics and antioxidant enzyme activities of greenhouse tomato. Photosynthetica 2016, 54, 28-39. [CrossRef]

24. Barry, C.S.; Aldridge, G.M.; Herzog, G.; Ma, Q.; McQuinn, R.P.; Hirschberg, J.; Giovannoni, J.J. Altered chloroplast development and delayed fruit ripening caused by mutations in a zinc metalloprotease at the lutescent2 locus of tomato. Plant Physiol. 2012, 159, 1086-1098. [CrossRef] 
25. Sivakumar, R.; Nandhitha, G.K.; Nithila, S. Impact of Drought on Chlorophyll, Soluble Protein, Abscisic Acid, Yield and Quality Characters of Contrasting Genotypes of Tomato (Solanum lycopersicum). Br. J. Appl. Sci. Technol. 2017, 21, 1-10. [CrossRef]

26. Barickman, T.C.; Kopsell, D.A.; Sams, C.E. Abscisic Acid Increases Carotenoid and Chlorophyll Concentrations in Leaves and Fruit of Two Tomato Genotypes. J. Am. Soc. Hortic. Sci. 2014, 139, 261-266. [CrossRef]

27. Landi, S.; De Lillo, A.; Nurcato, R.; Grillo, S.; Esposito, S. In-field study on traditional Italian tomato landraces: The constitutive activation of the ROS scavenging machinery reduces effects of drought stress. Plant Physiol. Biochem. 2017, 118, 150-160. [CrossRef]

28. Monteiro, C.C.; Rolao, M.B.; Franco, M.R.; Peters, L.P.; Cia, M.C.; Capaldi, F.R.; Carvalho, R.F.; Gratao, P.L.; Rossi, M.L.; Martinelli, A.P.; et al. Biochemical and histological characterization of tomato. An. Acad. Bras. Ciênc. 2012, 84, 571-585. [CrossRef] [PubMed]

29. Ünyayar, S.; Çekıç, F.Ö. Changes in Antioxidative Enzymes of Young and Mature Leaves of Tomato Seedlings under Drought Stress. Turk. J. Biol. 2005, 29, 211-216.

30. Milosavljević, A.; Prokić, L.; Marjanović, M.; Stikić, R.; Sabovljević, A. The effects of drought on the expression of TAO1, NCED and EIL1 genes and ABA content in tomato wild-type and flacca mutant. Arch. Biol. Sci. 2012, 64, 297-306. [CrossRef] 